\title{
MASCULINIDADES EN INDIANA JONES AND THE TEMPLE OF DOOM (SPIELBERG 1984)
}

\author{
José Díaz-Cuesta \\ Universidad de La Rioja \\ jose.diaz-cuesta@unirioja.es

\section{Introducción}

En el año 2006 se pone en valor la obra de Steven Spielberg en el ámbito académico anglosajón con la publicación de dos obras de muy diferente calado. Se empieza a rellenar el importante hueco que suponía que no hubiera monografías académicas en inglés sobre su obra.

La primera de esas obras la firma Warren Buckland, prestando atención a aquellas películas del director que han tenido más éxito en la taquilla, y centrándose en una aproximación técnica a aquellas opciones de Spielberg que definen la forma que tiene de narrar. La segunda procede de la pluma de Lester Friedman, feroz defensor del director ${ }^{1}$ en todas sus obras. En este libro las películas de Spielberg aparecen agrupadas por géneros: Indiana Jones and the Temple of Doom (1984) pertenece, según esa tipología, al conjunto de action/adventure melodramas, en el que Friedman distingue, por un lado, The Sugarland Express (Spielberg 1974) y Catch Me If You Can (Spielberg 2002), y, por otro, la de momento trilogía de Indiana Jones.

Según Friedman:

Unlike conventional action/adventure movie characters, Spielberg's figures ultimately discover that their most important quest is for inner knowledge, emotional depth, and psychological fulfillment rather than material gains or public glory. (Friedman 2006: 118)

En este artículo nos preguntamos si la búsqueda principal de Indiana Jones en este texto fílmico es la de desarrollarse como padre, que constituiría uno de los rasgos caracterizadores de la masculinidad representada por el arqueólogo. Continuamos de esta manera la exploración inicialmente realizada sobre Raiders of the Lost Ark (Spielberg 1981), primera película de la saga (Díaz-Cuesta 2005).

\footnotetext{
${ }^{1}$ En España, como hemos señalado en Díaz-Cuesta (2005), tanto David Caldevilla Domínguez (2005) como Antonio Sánchez-Escalonilla $(1995,2005)$, han contribuido a situar al director en el objetivo académico gracias a sus tesis doctorales, que han alcanzado pública difusión en formato divulgativo. Entre ambos, de nuevo en inglés, Yosefa Loshitzky (1997) y Charles Silet (2002) han aportado compilaciones de artículos dedicados a la obra spielberguiana.
}

Recibido: 01/03/2007---Aceptado: 16/04/2007---Publicado: 12/11/2007 


\section{Acerca del método}

Seguimos utilizando el método analítico-sintético con el que se llevó a cabo la exploración de masculinidades en Raiders of the Lost Ark (Spielberg 1981), haciendo uso de los cuatro sites o entornos propuestos por Pat Kirkham y Janet Thumim (1993: 11) a la hora de abordar la representación de masculinidades en textos fílmicos: el cuerpo, la acción, el mundo externo y el mundo interno.

Un hombre o un personaje ven definida su masculinidad como un rasgo de su personalidad o de su caracterización. Seymour Chatman (1986: 126) considera que los personajes están formados por conjuntos de rasgos en los que no llega a incluir la masculinidad. Kirkham y Thumim prestan toda su atención precisamente a esa característica ausente en Chatman en la introducción de You Tarzan: Masculinities, Movies and Men, obra compuesta de diversos artículos escritos por hombres sobre las representaciones de masculinidades en diversas películas. En su introducción, las editoras sintetizan todas esas aportaciones en los cuatro entornos mencionados.

Esos cuatro sites no difieren apenas de los ambientes que explora Raewyn Connell en su monografía Masculinities (1995), en la que desde un punto de vista sociológico estudia masculinidades presentes en Australia a través de una serie de entrevistas a hombres que reflejan lo que piensan sobre sí mismos.

Cada uno de los siguientes apartados se centra en un entorno de los considerados por Kirkham y Thumim, sin considerarlos compartimentos estancos, de tal manera que el contenido de alguno de ellos puede permear en otros, y es posible reconsiderar una escena en concreto atendiendo a los diferentes perfiles que proporcionan entornos distintos ${ }^{2}$.

\section{El cuerpo en Indiana Jones and the Temple of Doom}

Siguiendo a Kirkham y Thumim, cuando se trata de explorar el cuerpo o cuerpos que sustentan las masculinidades de una película debemos ocuparnos, además de la forma en la que son mostrados, de la star persona desplegada por los actores cuyos cuerpos sostienen los personajes.

En Temple of Doom, como ya sucedía en Raiders, el protagonismo masculino está principalmente encabezado por el actor Harrison Ford.

Entre estas dos películas Ford sólo aparece en otras dos, siendo una de ellas la tercera entrega de la saga galáctica dirigida por George Lucas, Return of the Jedi (1983), en la que vuelve a interpretar el personaje del aventurero Hans Solo, y la otra Blade Runner (Scott 1982), película que ha acabado convirtiéndose en un

\footnotetext{
${ }^{2}$ Además del artículo anterior sobre Raiders puede consultarse otro artículo de nuestra propia autoría en el que se analiza una película previa del director, Jaws (Spielberg 1975), haciendo uso de este mismo patrón analítico (Díaz-Cuesta 2003), y, en referencia a las trazas míticas de la trilogía de Indiana Jones: Díaz-Cuesta 1998.
} 
clásico de la ciencia ficción y el cine negro. El personaje de Rick Deckard que Ford encarna en esta obra ahonda en la consideración del actor como un hombre normal y corriente, con la duda de si podría tratarse de un replicante, una máquina no humana pero capaz de experimentar sentaciones y sentimientos que le acercan a los hombres, como deja patente Roy Batty, el personaje interpretado por Rutger Hauer en el emotivo discurso previo a su muerte o eliminación en el film.

Ford continúa vinculado a personajes repletos de acción y con ciertas inquietudes metafísicas. Su atractivo físico se había visto propulsado por la popularidad de estas dos películas, y sobre todo por la gran taquilla recaudada por Raiders.

Procedemos ahora con el otro aspecto del cuerpo, el de su representación factual en el texto fílmico.

Si al analizar Raiders estábamos de acuerdo con Andrew Rissik (1984: 13) al considerar la influencia del personaje de James Bond en toda la saga de Indiana Jones, en el caso de Temple of Doom esa influencia casi roza la parodia en la secuencia en la que aparece por vez primera en el film. Tras la escena inicial, más propia de un musical que de una película de acción y aventuras, nos encontramos con un Indiana Jones que difiere en su representación de las diversas maneras en las que se había mostrado en Raiders.

Lo primero que divisamos de Jones en esta película son sus piernas (F01a, F01b, F01c), sobre las que viste un pantalón negro que contrasta con las piernas de las coristas que han aparecido en la escena inicial, sobre la que se han inscrito los créditos principales, incluido el del director y el de la localización y la fecha de la acción, Shanghai, 1935: un año antes de lo que sucede en Raiders, con lo que la ficción de Temple of Doom se puede catalogar como precuela frente a la primera película.
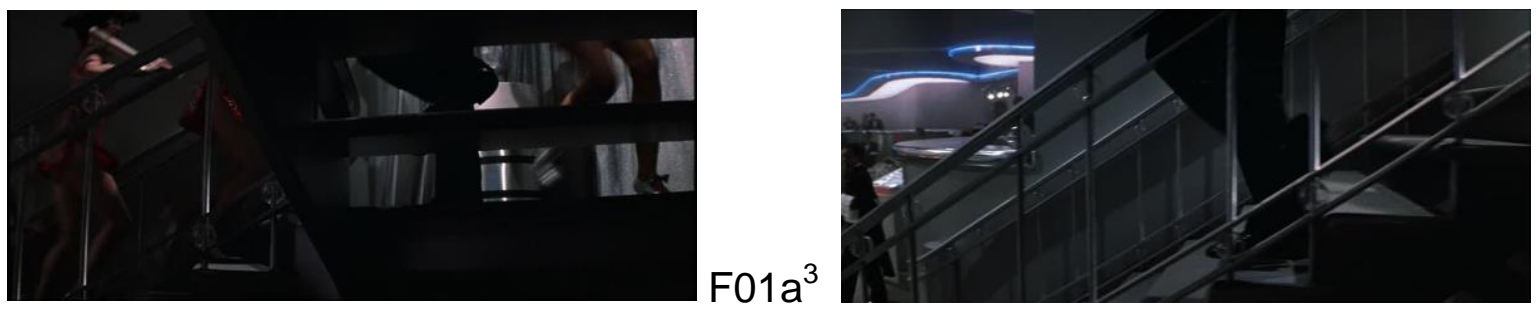

F01b

\footnotetext{
${ }^{3}$ La letra minúscula al final de la notación de imágenes con la misma numeración indica que esos fotogramas pertenecen a la misma toma.
} 


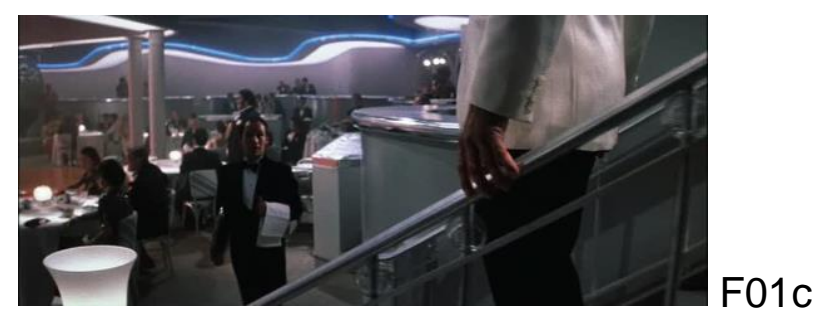

El contraste con las chicas del coro también se localiza en la dirección de sus movimientos: hacia arriba en el caso de las mujeres, hacia abajo en el del hombre: esa dirección, hacia abajo, será una constante para Indiana Jones en este texto fílmico. En ese movimiento es posible ver más del cuerpo de Jones, en concreto de su espalda, sobre la que lleva puesta una chaqueta blanca. Nadie más va vestido así. De hecho, aunque la paleta de colores se mantiene, el resto de clientes masculinos del local van ataviados con chaqueta negra, incluido el colaborador de Jones, disfrazado de camarero. En breve veremos que hay una razón añadida para esta disociación de colores. El juego de referencias a películas musicales de la secuencia inicial y este nuevo atuendo del arqueólogo contribuyen a crear dudas sobre si será él quien se esconde tras esa chaqueta y esos pantalones

Sería posible confundirle con James Bond, que también viste esmoquin blanco en Goldfinger (Hamilton 1964), en la piel de Sean Connery (F02), y en Octopussy (Glen 1983) en la de Roger Moore (F03).
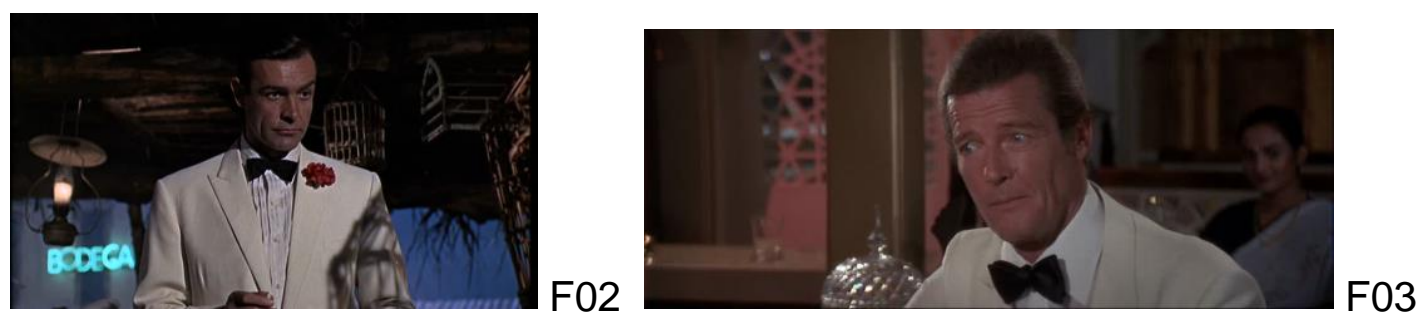

De hecho, cuando George Lucas le propuso a Spielberg realizar esta saga, al segundo le habría gustado dirigir una película sobre 007. Pero aún hay otra referencia de peso en este Jones de chaqueta blanca: el Rick Blaine interpretado por Humphrey Bogart en Casablanca (Curtiz 1942). De hecho cuando ha aparecido Jones en pantalla se han podido discernir las notas de una melodía al piano, diferentes de las que suenan en el film de Michael Curtiz, pero sirven igualmente de recordatorio de aquella película. Se indica así que el arqueólogo se mueve perfectamente en ese ambiente, casi tanto como si fuera el dueño del local, como es el caso de Rick. El paralelismo visual entre ambos llega al extremo de que Jones aparece en la misma posición y realizando el mismo gesto que Rick (F04, F05 IJ2): 
más allá del homenaje específico de ese momento, se está convocando toda una película, aunque sea para finalmente desviarnos por otro camino.
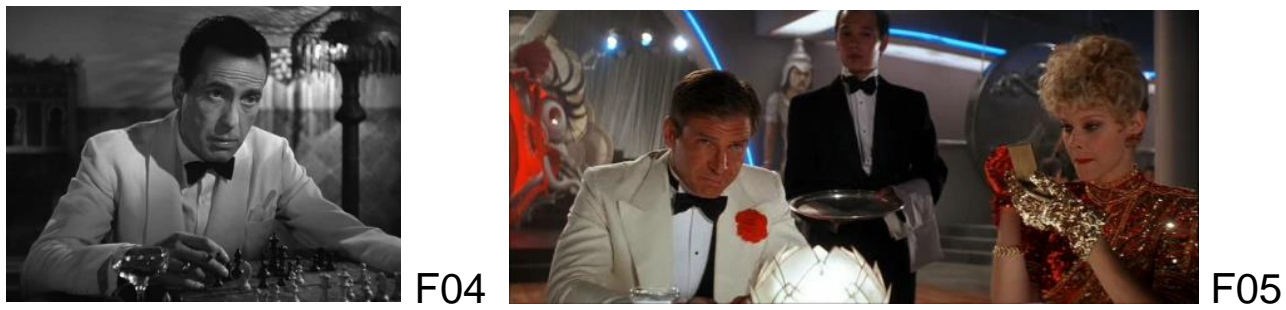

Pero el hecho de que en un mismo personaje confluyan las referencias a James Bond y a Rick Blaine no debería considerarse una cuestión baladí: con esta introducción se está cargando de poder mitificador a la figura del arqueólogo, de un poder que podríamos demoninar sincretizador de las características de ambos personajes de ficción. Esa capacidad será eventualmente considerada en su vertiente cómica en el caso de Bond y en su acercamiento a los sentimientos de los demás en el del protagonista de Casablanca.

Se ahonda de esta manera en ese engaño genérico-visual que lleva a cabo Spielberg al comienzo de esta película. Como él mismo reconoce, sus intenciones eran:

To mislead the audience and make them think, with the dancing girls and exotic charactes and their colorful costumes, that Indiana Jones' adventure was going to take place on the surface of the world. But the minute he goes into his room at night and discovers the secret passage which leads into the inner sanctum and eventually to the Temple of Doom, I wanted the shift in style to very dark and low key. (Elkins 1984: 55)

El paso por la caracterización como Bond/Rick hace las veces de elemento de transición hacia ese descenso oscuro y poco iluminado.

El contraste que hemos señalado con respecto al resto de ocupantes masculinos del salón alcanza su máxima expresión cuando Jones se encara con su oponente, Lao Che (Roy Chiao), que lleva los colores inversos: chaqueta y camisa negras, pajarita blanca (F06). Una clara contraposición de colores, con una asociación tradicional del blanco al bueno de la película, y el negro al malo. 


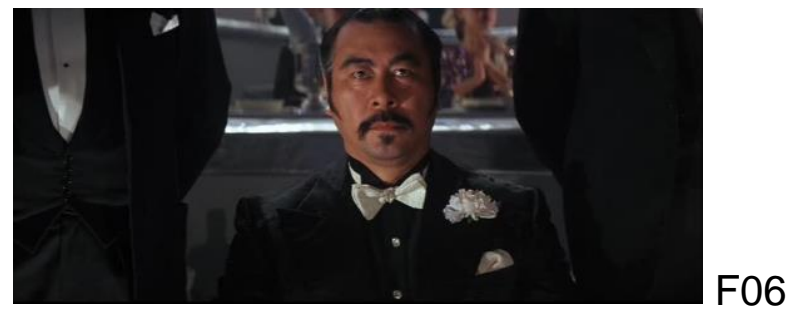

Pero esa distinción tan clara se rompe en cuanto vemos a Indiana Jones de nuevo, con la memoria evocando Raiders, vistiendo su atuendo más reconocible (F07a), saliendo de una puerta del avión del que tendrán que saltar en pleno vuelo. Su apariencia le hace decir a Willie Scott (Kate Capshaw): "What are you supposed to be, a lion tamer?" (F07b). La pregunta tiene algo de sentido por la apariencia de Jones con su látigo, aunque cuando les habían presentado, Jones ya había sido introducido como arqueólogo. Los diálogos de Scott con Jones se prestan en la mayoría de las ocasiones a proporcionar el comic relief de la historia.
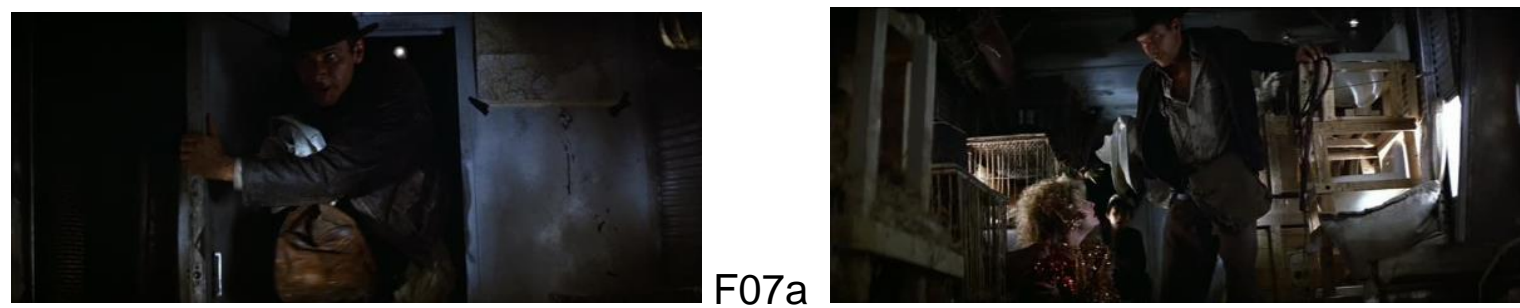

F07b

Siguiendo con la estela de referencias, homenajes e influencias que se hacen notar en el film, podemos citar el hecho de que los traicioneros pilotos del avión lo abandonan, dejándolo sin gobierno y sin combustible, algo muy similar a lo que sucede en la película Lost Horizon —dirigida por Frank Capra en 1937-, similitud que afecta incluso al momento del film en el que ocurren estos sucesos. Allí el desvío y accidente del avión conduce hacia un lugar utópico denominado ShangriLa. En el caso de Temple of Doom sucede todo lo contrario, ya que lo que se encuentran sus protagonistas es un universo cada vez más distópico, en el que el mal reina sobre todos.

Tanto Casablanca como Lost Horizon se sitúan alrededor de las fechas en las que tuvo lugar la Segunda Guerra Mundial, a la que se había hecho amplia referencia en Raiders. Los cuerpos de los personajes masculinos de Temple of Doom necesitan estar preparados para la guerra: el descenso a los infiernos que supone la película se ofrece como una buena forma de llevar a cabo esa preparación. 
A pesar de que en esta película Jones no pasa en ningún momento por la universidad, sí podemos verle con su apariencia más académica, con ropas prestadas en el palacio del marajá (F08a). Se recupera el traje de lana y la pajarita, así como sus gafas. Cabe preguntarnos para qué las necesita Jones, dado que cuando va vestido de aventurero no parecen hacerle falta, ni para ver de lejos ni para mirar cosas cercanas. Ciertamente contribuyen a su mayor aire intelectual con esta apariencia general, pero el tipo de reflejo que producen hace pensar que están realmente graduadas, lo que le produciría problemas en la vista al usarlas si no las necesitara, o falta de visión al no usarlas si dependiera de ellas. En parte aquí nos debemos a la suspensión del descreimiento necesario para que aceptemos la ficción.
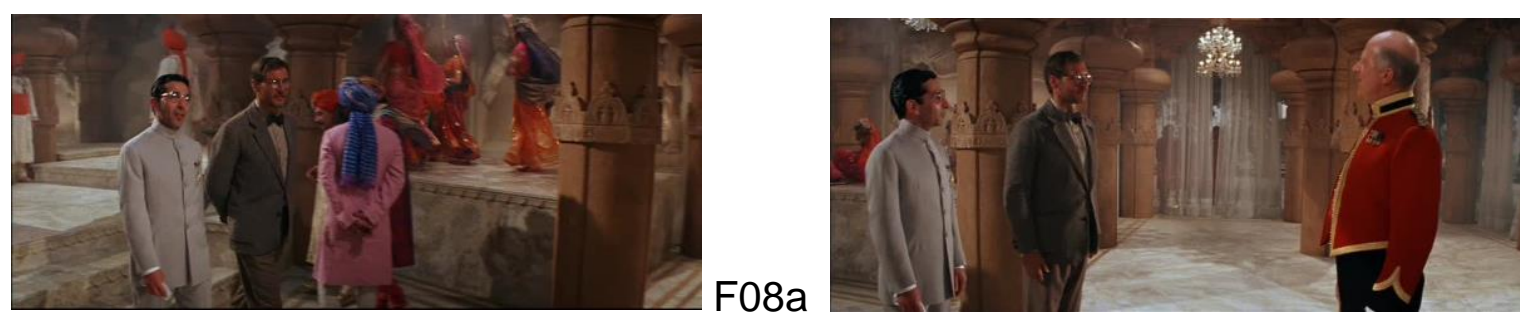

$\mathrm{F} 08 \mathrm{~b}$

El capitán Blumburtt, del undécimo batallón de rifles de Poona, reconoce a Jones con la frase "And you sir, are Dr. Jones, I presume?" (F08b) parodiando la famosa cita de Henry Morton Stanley dirigida a David Livingstone cuando el primero le dijo al segundo "Dr. Livingstone, I presume?": hecho histórico supuestamente ocurrido en 1871, aunque la veracidad de la frase no ha podido ser corroborada. De nuevo se está asimilando a Jones con una figura de proporciones míticas, en este caso otro doctor, en el sentido estrictamente académico de la palabra, vinculado a la investigación académica y sobre todo a la exploración de culturas desconocidas hasta ese momento para los occidentales.

Ese plano en el que capitán y arqueólogo se dan la mano expone la mezcla de culturas que se estaba produciendo en el ámbito indio en la época, con el Primer Ministro ataviado con un traje a mitad de camino entre lo occidental y lo oriental, Jones con su apariencia académica y Blumburtt con su uniforme de gala. No en vano, el Primer Ministro realiza una crítica de la vigilancia británica de su territorio. Un tema, el del imperialismo colonialista, que no le es ajeno al productor de esta película, George Lucas, por sus connotaciones con la saga galáctica que ha dirigido. La Segunda Guerra Mundial sigue rondando las comisuras del guion, así como otras obras que estaban por venir dirigidas por Spielberg, como Schindler's List (Spielberg 1993) y Saving Private Ryan (Spielberg 1998). 
La preocupación por la apariencia del cuerpo se patentiza cuando Jones y Scott se preparan para tener un encuentro amoroso. Se produce un montaje en paralelo de ambos acicalándose (F09, F10, F11, F12) que años más tarde sería recuperado en la escena de afeitado de Oskar Schindler y Amon Goeth en Schindler's List (Spielberg 1993). Aquí se incide sobre la igualdad de los sexos a la hora de prepararse para la acción amorosa, como veremos al volver sobre esta escena en el apartado dedicado al entorno externo.
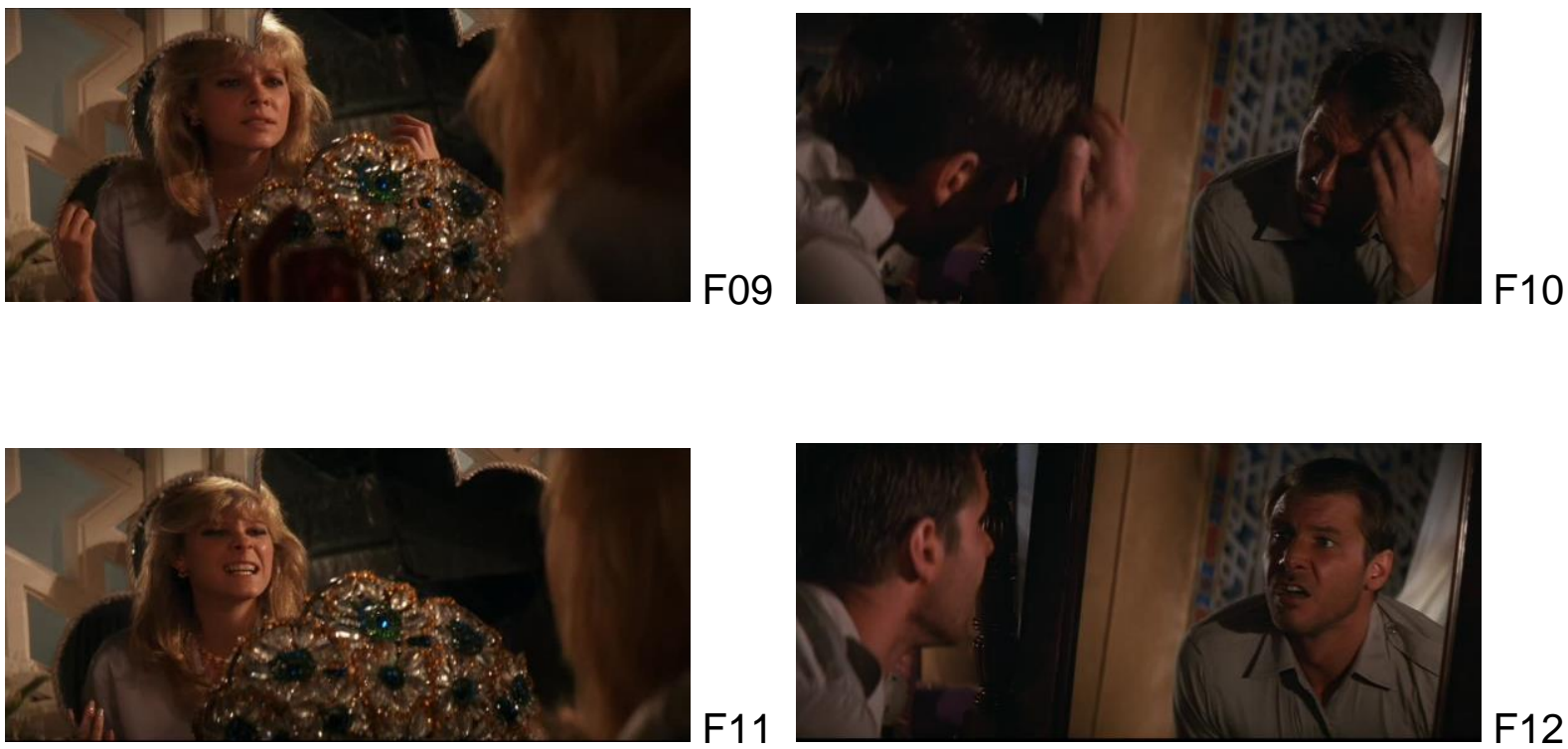

F11

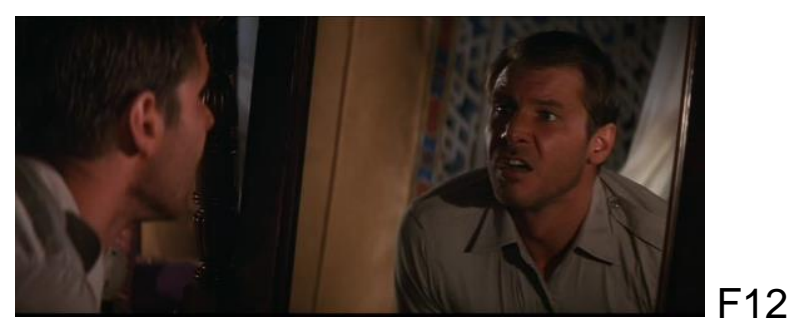

El cuerpo de Jones no podía dejar de sufrir en esta película. Así, lo vemos retorcerse tras haber tomado la droga que anula su voluntad (F13, F14), y cuando ya ha sido vencido por el brebaje, la expresión del rosotro de Ford/Jones cambia en una misma toma en primer plano, de la duda (F15a) al convencimiento (F15b).
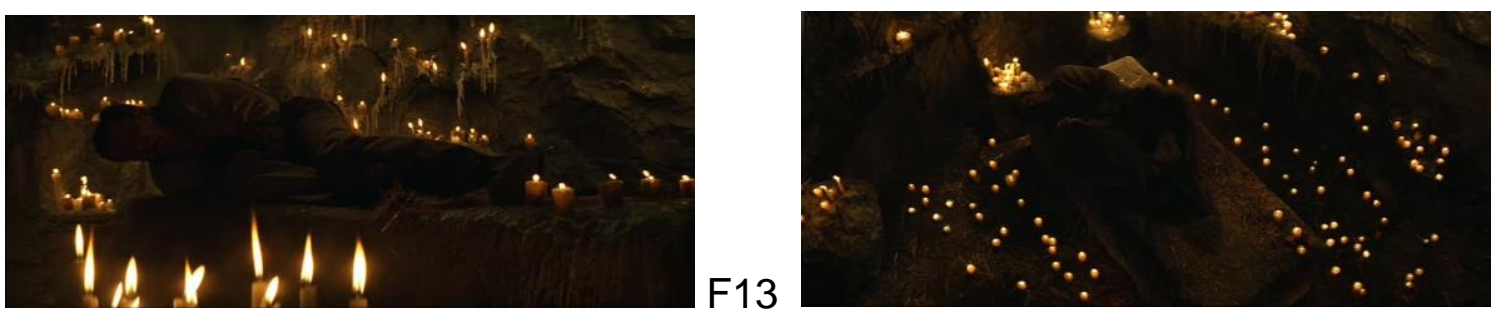

F14 

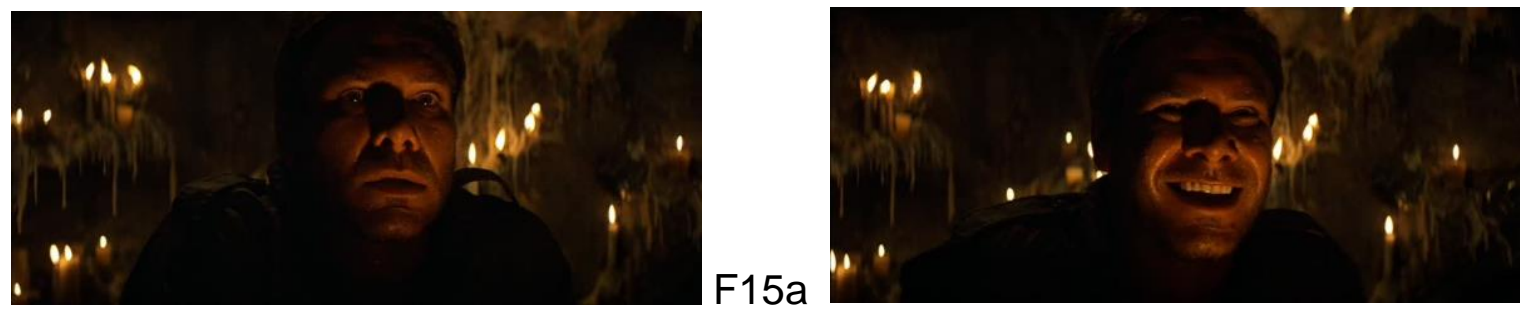

$\mathrm{F} 15 \mathrm{~b}$

Un recurso importante que supone una evolución respecto a la película anterior lo constituye el hecho de que en ésta sí vemos claramente el torso del arqueólogo desnudo (F16). Se alienta de esta manera el deseo en la mirada de quien le contempla, o al menos la admiración, dependiendo de la orientación sexual de cada espectador/a. Como nos recuerdan Kirkham y Thumim (1993: 13), "The question of who keeps their shirt on and who doesn't is an important one". A diferencia de Raiders, en la que quien se quitaba la camisa era el nazi pugilista de la escena que termina con un avión explotando, en Temple of Doom el protagonista asume el deleite en la mirada de quien está viendo la película. El plano contrasta, por otra parte, con el de una de las víctimas de la secta al que Mola Ram (Amrish Puri) le extrae el corazón con la mano (F17): se plantea la duda de si Jones sufrirá la misma suerte, o si será la chica a quien se le extraiga el corazón.
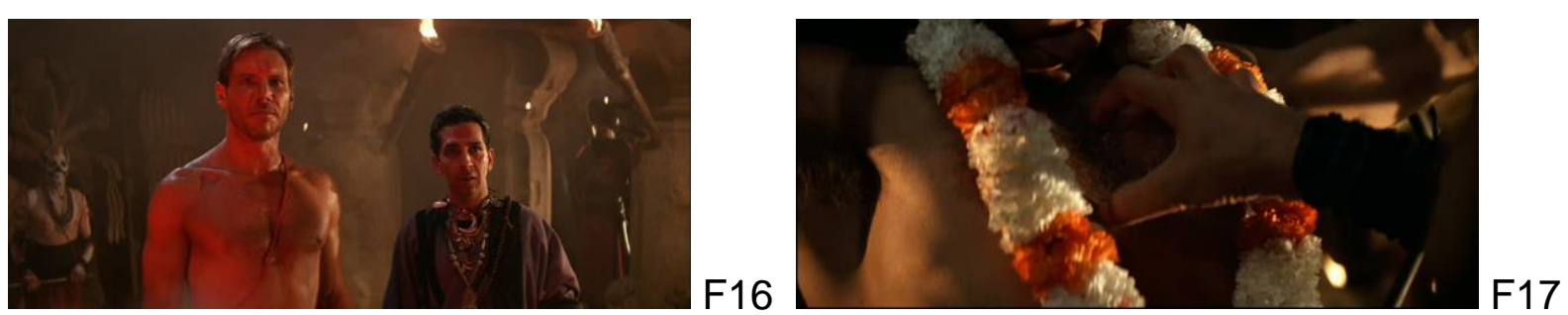

En Temple of Doom hay un plano que recuerda, por un lado, a la presentación de Jones en la primera película, y, por otro, a la aparición de los superhéroes en los comics cuando quieren sorprender e impresionar a sus enemigos. Además el plano incorpora una de las firmas identificadoras del director, al situar una gran fuente de luz tras el personaje, que aparece casi a contraluz (F18). 


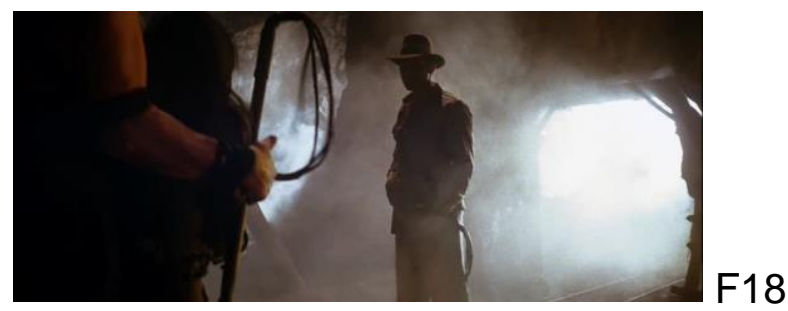

Se recupera al Jones decidido de la película anterior, y todas esas connotaciones hacen que queramos identificarnos más y más con él. Lo que se había buscado en Raiders, que Jones fuera reconocible por su silueta, se consigue en Temple of Doom gracias al recuerdo de la primera entrega. Pero en la segunda película ha hecho falta llegar al momento previo a la persecución final en la mina para que se produzca ese reconocimiento: durante todo el tiempo anterior se ha estado jugando con las expectativas del espectador.

\section{La acción en Indiana Jones and the Temple of Doom}

Aunque nos encontramos evidentemente ante una película de acción y aventuras, la acción —entendida como la del cuerpo o cuerpos masculinos - se sitúa en niveles muy diferentes de los establecidos en Raiders. La escena de baile y canto de los créditos desconcierta en principio al espectador, y las escenas siguientes, que suponen la entrega de la reliquia y la búsqueda del antídoto, contribuyen aún más a ese desconcierto, ya que esperamos encontrarnos a Jones en un ambiente de hallazgos arqueológicos sobre el terreno, y en su lugar nos topamos con un pseudo-Bond/pseudo-Rick en Casablanca intentando localizar el antídoto del veneno que se acaba de beber en una escena que parece una continuación coreografiada de la escena musical de los créditos iniciales.

La escapada del club Obi Wan con Willie Scott recuerda tanto a las películas cómicas del cine mudo como a las de aventuras y a los seriales en los que se había basado Raiders. Su introducción en Temple of Doom incorpora un comentario metaficcional al final de la escena, cuando Short Round (Jonathan Ke Quan) exclama "Wow. Holy smoke! Crash landing!". Este personaje constituye uno de los ejes sobre los que pivota la identificación del espectador, sobre todo de los más jóvenes de la audiencia. A partir de ese momento las acciones de ambos cuerpos, las de Jones y las de Round, se mostrarán a menudo interconectadas.

El actor que da vida a Short Round, Jonathan Ke Quan, aparecería al año siguiente co-protagonizando The Goonies (Donner 1985). Aunque esa película no fue dirigida por Spielberg sino por Richard Donner, es posible discernir un gran hilo 
de continuidad genérica con la saga de Indiana Jones: de hecho la historia inicial procede de Spielberg, que también hizo labores de productor ejecutivo, y en numerosas ocasiones se le ha apuntado como director en la sombra de esta película para niños. Es como si con The Goonies Spielberg hubiera querido compensar a su audiencia más joven y a sí mismo por la oscuridad de Temple of Doom. Resulta interesante citar a Susanna White, una graduada en estudios fílmicos, a la que justo antes de graduarse le preguntaron cuál era su película favorita tras los estudios cursados. A diferencia de sus compañeros, que se inclinaron por Jean-Luc Godard o por algún cortometraje del expresionismo alemán, ella declaró que su película favorita era la misma que cuando tenía siete años, y lo justifica, en parte, precisamente por lo que hay de Indiana Jones en este film:

People may say it's an Indiana Jones wanna-be I think that is the defining beauty of it all. When we first watched The Goonies it was like watching our dreams come true on screen! We'd loved seeing Indiana's adventures and escapades and in The Goonies we saw kids like us actually doing it! They got to be just like the mini-Indies we imagined ourselves to be in the playground. (White 2004)

De manera que no nos debemos extrañar de que cuando Indiana Jones recupera el sentido tras haber bebido el brebaje hipnotizador, Short Round también cobra un mayor protagonismo (F19): de hecho ha sido el propio niño quien ha devuelto a la realidad al arqueólogo tras haber sido el mismo Round quien ha logrado escaparse de las cadenas que le atenazaban. Cuando Jones vuelve a ser él mismo, niño y adulto atacan a sus captores de manera coordinada (F20).
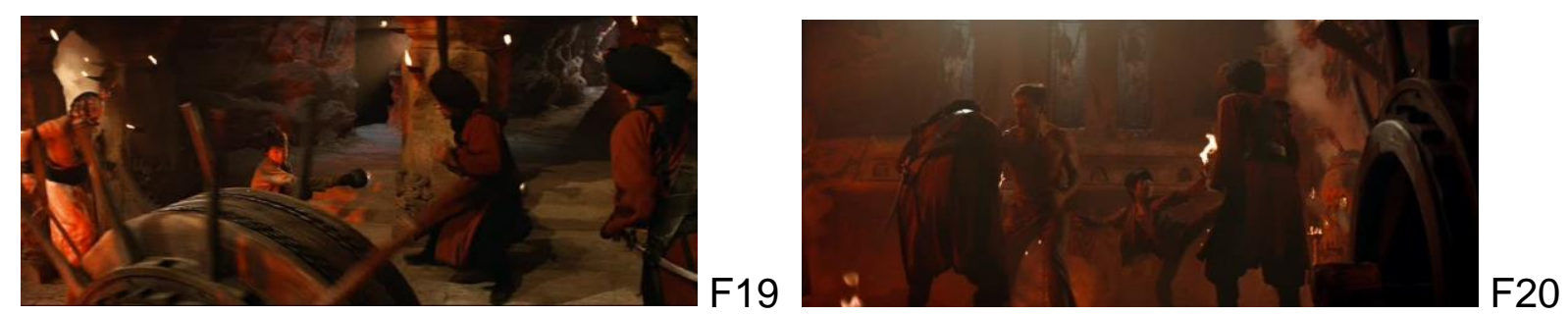

Resulta particularmente expresivo el plano que muestra a Round dando golpes al aire, siguiendo la pelea que está manteniendo Jones en ese momento (F21), mientras la sombra de los dos contendientes se proyecta a su lado y por encima de él: Spielberg, por un breve instante, contiene su película en un juego de sombras con el que el espectador más joven se puede identificar por completo, como si el espectador imaginario hubiera irrumpido en la pantalla. 


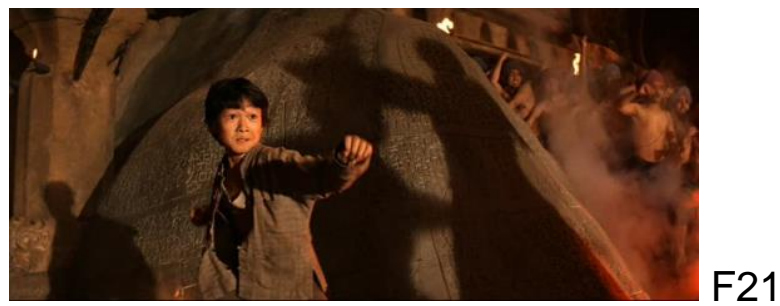

El momento de mayor enfrentamiento físico, el cuerpo a cuerpo de este film, sucede entre Jones y un esbirro del marajá. A diferencia de lo que había sucedido en Raiders, donde la astucia del arqueólogo le había proporcionado gran ventaja en la escena equivalente, aquí no es capaz de recurrir a artimañas, y necesita de la ayuda de Round, que tiene que librarse de las manos protectoras de Scott para "salvar a Indy", como él mismo dice (F22). De aquí deducimos que la acción en Temple of Doom, aunque nos refiramos a ese entorno de la representación de la masculinidad de Indiana Jones, no alcanza su plenitud sin la presencia y colaboración de un niño.

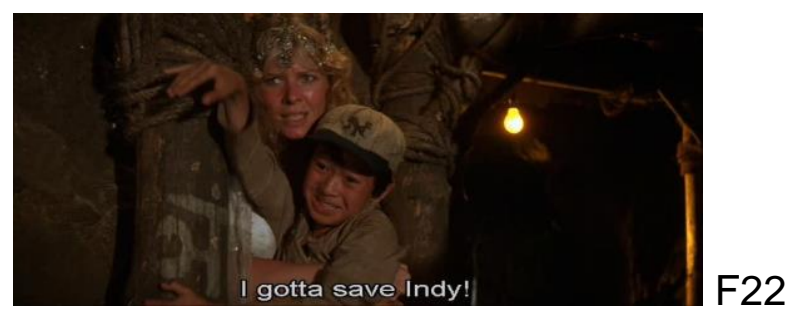

Niño y arqueólogo son mostrados en tomas consecutivas golpeando a sus enemigos (F23, F24), ahondando en el paralelismo y la identificación entre ambos. No debemos pasar por alto el ejercicio de vudú que realiza el marajá sobre un muñeco con la apariencia de Jones: puede interpretarse como una metáfora de lo que le sucede al espectador viendo la película: lo que les ocurre a esos personajes en la pantalla tiene consecuencias en el ánimo y en el sentir de quien lo está viendo desde una butaca.
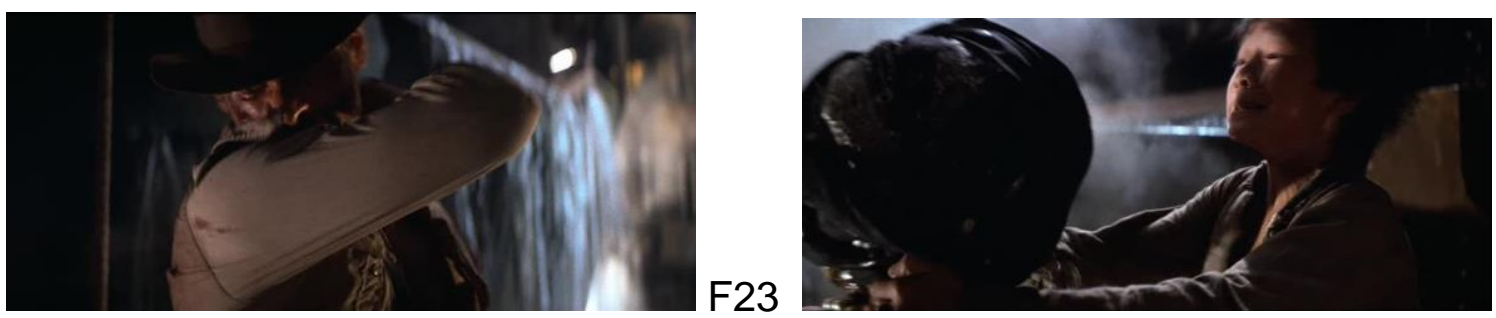

F24 
La escena de acción más espectacular, por la que en ocasiones se recuerda esta película, se corresponde con la huida en la vagoneta de la mina. Los prolegómenos incluyen las diversas formas de subirse a la vagoneta de cada uno de los tres protagonistas: Scott boca abajo, Round escalando por encima de un esbirro y Jones colgado de una cuerda. Consiguen reunirse en la vagoneta justo antes de que éste se aventure en el túnel de entrada al circuito ${ }^{4}$, como quien ha conseguido la entrada para un viaje en una montaña rusa. De hecho el circuito es una montaña rusa, como señala el propio Spielberg:

What we actually did was build a rollercoaster ride on the sound stage. And it really worked. It was safe. It was electrically driven. You could take rides in it. (Spielberg en Elkins 1984: 57)

Se produce una vez más un bucle metaficcional por el que los personajes entran en una atracción (F25) con la que fácilmente se pueden identificar los espectadores, que luego pueden reproducir subiéndose a cualquier montaña rusa o a la específica en Disneyland ${ }^{5}$. El momento de mayor tensión lo protagoniza de nuevo el niño, al quedar sujeto entre dos vagones que circulan en paralelo (F26): se le inflinge a ese cuerpo una nueva tortura, la del estiramiento, en una velada metáfora a lo mayor que se está haciendo viviendo esta aventura para mayores.
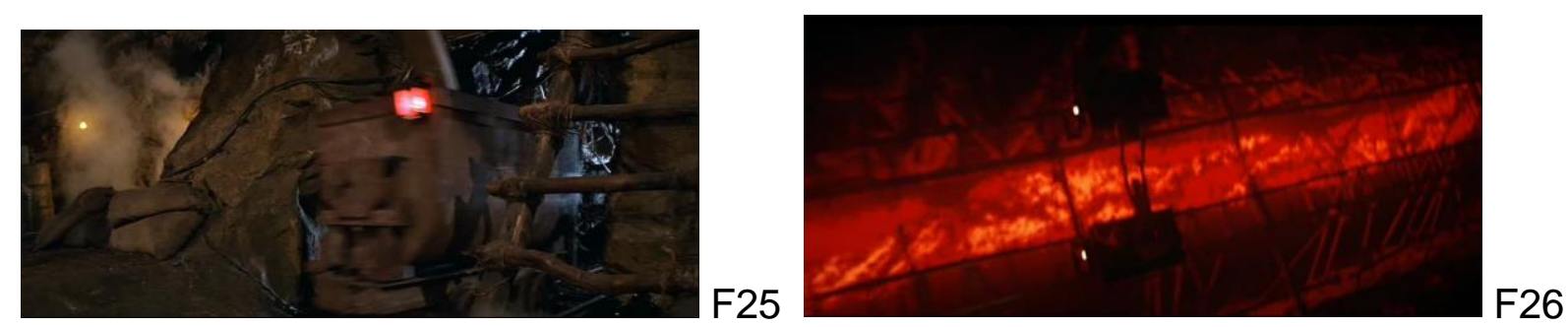

Tras volar, literalmente, con el vagón por los aires, y quedarse sin frenos, Jones es capaz de detener la vagoneta con la mera ayuda de su cuerpo y sobre todo sus pies (F27), en una acción más propia de Superman que de un arqueólogo, por muy aventurero que sea. La exageración se compensa con la comicidad derivada de la petición de agua de Jones para remojar sus pies, petición que tiene como respuesta la tromba que inunda la mina.

\footnotetext{
${ }^{4}$ Spielberg revela en American Cinematographer que utilizaron un circuito que fue fotografiado desde numerosas posiciones para dar la sensación de que se estaba realizando un recorrido mucho más largo (Elkins 1984: 57, 59).

${ }^{5}$ Curiosamente, la atracción la ofrece Disney y no Universal, fruto de un acuerdo entre George Lucas y los estudios Disney.
} 


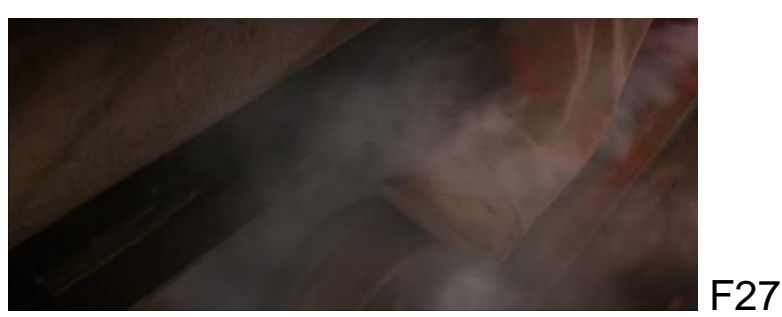

La comicidad vuelve a estar presente cuando poco después, a punto de acceder al puente colgante que acabará cortando en dos pedazos, es atacado por dos esbirros armados con enormes espadas, ante los cuales reacciona como en la película anterior, solo que esta vez teniendo que darse cuenta de que no lleva la pistola consigo. No es posible interpretar la escena en clave de comedia si no se ha visto Raiders previamente: Spielberg juega con esa posibilidad tanto en este momento como en el resto de la película, y por eso creemos que se ha podido permitir el lujo de relegar las acciones más valerosas del héroe para los últimos compases del film.

Scott, cuando es apercibida por Round de la acción que va a realizar Jones seccionando el puente exclama: "Oh my God! Is he nuts". A lo que el niño responde: "He no nuts, he crazy": se cuestiona la valentía tiñéndola de temerariedad o simplemente de locura. A diferencia de lo que sucede con los superhéroes, cuyas habilidades son normalmente veneradas por la mayoría, algunas de las ocurrencias de Jones no son bien recibidas ni por aquellos a quienes supuestamente va a beneficiar.

Esta última escena de acción del film en el puente culmina con un epíteto del héroe aventurero, al borde de un precipicio, sin que se le haya caído el sombrero, y blandiendo en una mano la piedra en cuya busca había ido (F28). Spielberg logra darle una ligera vuelta a la idea del cliffhanger al situar precisamente en el final de la peripecia al protagonista colgando de un precipicio.

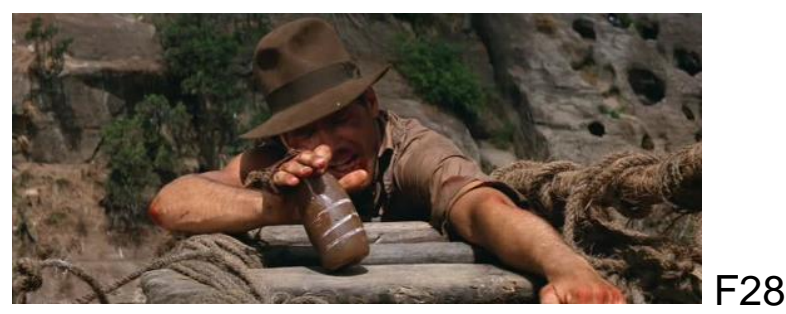




\section{El mundo externo en Indiana Jones and the Temple of Doom}

La última aparición del héroe en Raiders sucede del brazo de la mujer con la que ha mantenido una tensión sexual no resuelta a lo largo de toda la película (DíazCuesta 2005). En Temple of Doom, la secuencia de créditos iniciales gira en su totalidad en torno a una mujer, Willie Scott: la relación que Jones establece con ella, salpicada de situaciones cómicas, constituye una trama paralela de la película. Pero Temple of Doom va más allá de querer emparejar al arqueólogo, al sernos introducido el nuevo personaje de Short Round, que claramente realiza las funciones de hijo adoptivo de Jones. El objetivo paralelo del film es re-unir a esta familia para que pueda ser considerada como tal, uno de los temas spielberguianos por excelencia.

Para ello se procede primero a la presentación de cada uno de sus miembros. La primera en aparecer, como acabamos de mencionar, es la mujer, Willie Scott, a quien da vida Kate Capshaw. Justo después de que hayamos podido leer que vamos a ver una película de Steven Spielberg (F29a), sobre la misma boca de fuego de un dragón, aparece el personaje de Scott, también vestido de rojo (F29b).
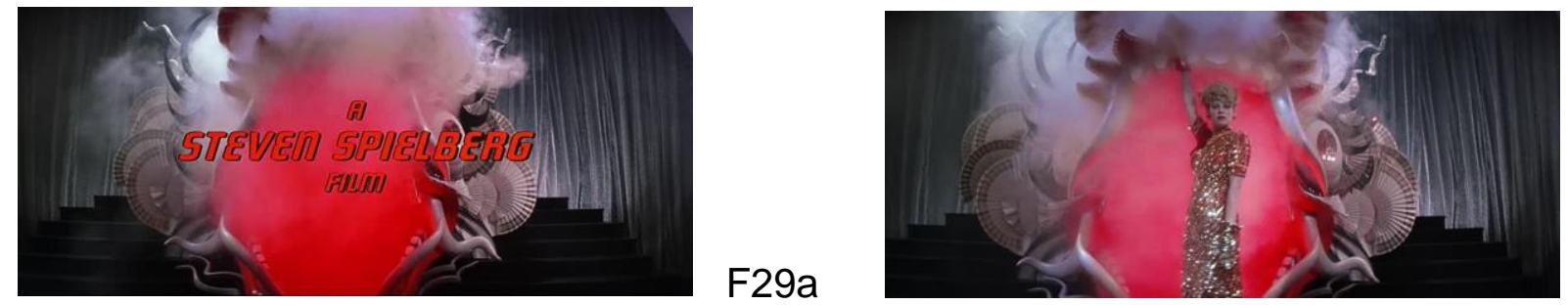

F29b

Tenemos que remontarnos a otra boca, la del tiburón en Jaws (Spielberg 1975), para recordar una imagen semejante en la filmografía de Spielberg. En aquella ocasión era un hombre, Quint, quien entraba por aquella boca, en una simulación de un retorno al seno materno (Díaz-Cuesta 2003: 184). En Temple of Doom asistimos al proceso contrario, el del alumbramiento, no de un hombre, sino de una mujer plenamente formada cuya voz y movimientos pretenden cautivar a los espectadores del club nocturno en el que se desarrolla la acción, y por ende a los espectadores de la película. Se personifica en ella la pasión sentimental: alza las manos y sujeta visualmente el nombre de Harrison Ford (F29c). Vemos a continuación el título de la película, pero sobre el mismo destaca la figura de Scott (F29d), de tal manera que se superponen tres planos: el del fondo con las bailarinas/coristas, el del título y el de Scott. 

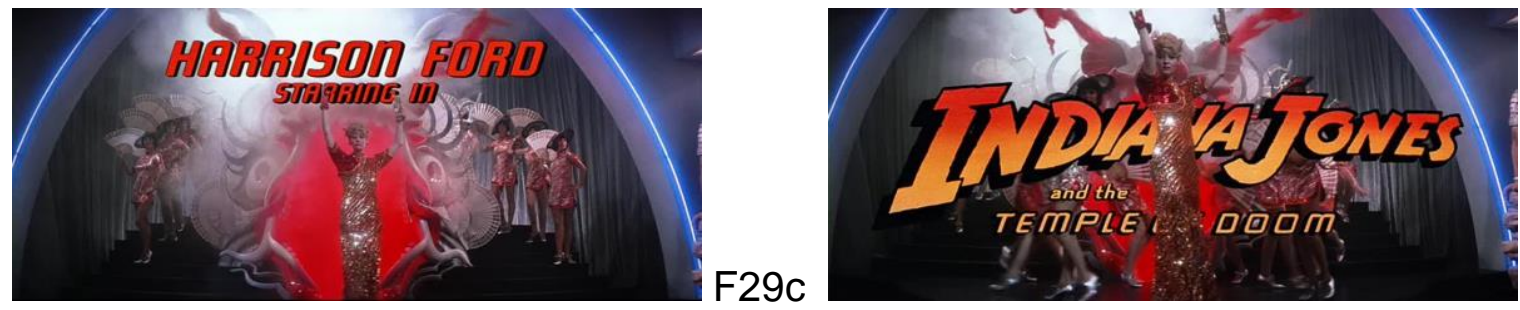

F29d

Subrayando el carácter protagónico del personaje, el nombre de la actriz que lo sustenta aparece inmediatamente después del título. Todos los créditos aparecen en rojo, como el vestido de la chica y de las coristas, como la flor que lleva Jones en la solapa en el club, como la lava que subyace en el templo maldito, como el corazón que extrae Mola Ram. Rojo de sangre y vida, rojo de sacrificio, rojo tradicionalmente asociado a la mujer: no en vano, ella es la víctima propiciatoria del sacrificio, precisamente cuando Jones está sometido por el brebaje hipnotizador.

Scott canta una versión china de "Anything Goes", de Cole Porter, tema central del musical del mismo título que se estrenó en Broadway en 1934, siendo interpretado por Ethel Merman (Anythig Goes Trivia 2006), actriz y cantante que luego protagonizaría la película musical homónima dirigida en 1936 por Lewis Milestone. Temple of Doom bebe directamente de ese texto fílmico, ya que Anything Goes también arranca con un número musical en el que únicamente se canta una breve estrofa de la canción. En la película de Spielberg, sin embargo, se nos ofrece una versión que parece completa, aunque está en chino mandarín, un idioma difícil de entender para los espectadores occidentales de $1984^{6}$.

Aparte de por la música, en Temple of Doom el tema es reconocible porque se respeta el verso en inglés que da título a la canción, "Anything goes". La frase, en la canción original de Porter, alude a lo descarado del mundo actual (de los años 1930), y a que el chico a quien se dirije aceptaría la propuesta de la chica si ésta se declarase. En cierta medida esa idea se mantiene en Temple of Doom, ya que se juega en parte con intentar darle la vuelta al estereotipo en las relaciones entre Jones y Scott. Pero sobre todo, lo que queda de la canción en el texto de Spielberg es ese "Anything goes", todo vale, de aplicación a toda la película: se invita a la suspensión del descreimiento desde el contenido de esa expresión y desde el recurso a la fantasía de un número musical que solo puede ser contemplado en su totalidad por el espectador de cine, y no por quienes están presenciándolo en el club Obi Wan: el paso al fuera de campo del espectador intradiegético se produce cuando Scott entra en la boca del dragón. Aunque la acción se sitúe con anterioridad a Raiders, la frase y la canción deben considerarse en relación con la película que

\footnotetext{
${ }^{6}$ En los años cincuenta el tema había sido recuperado por Frank Sinatra y por Ella Fitgerald. Sinatra incluso compartió cartel con Merman en una versión reducida del musical para televisión emitida en 1954.
} 
fue estrenada primero y que la mayoría de los espectadores de Temple of Doom ya había visto: en Raiders se presentó en sociedad a Indiana Jones, ahora que ya se le conoce se puede uno preparar para la sorpresa, porque todo vale.

La dirección y el sentido del movimiento relacional que se establece entre Jones y Scott se realiza de ella a él, ya que es la vocalista quien le pide a Lao Che (Roy Chiao) que le presente al arqueólogo. Al definirlo Che como tal, como "famous archaeologist", Scott responde "Well, I thought archaeologists were these funny little men searching for their mommies". La chica cataloga a los arqueólogos como hombrecillos y añade que están buscando a sus mamás, a lo que Jones le corrige precisando que se trata de mummies, momias. En inglés americano, que es el que usan ambos, existe diferencia en la ortografía y pronunciación de ambas palabras, y probablemente el chiste fuera manido. Pero la literalidad de la frase indica que ella creía que los arqueólogos buscan a sus mamás, y/o que posiblemente no sepa a qué se refiere el término mummies, en alusión a su falta de conocimientos de todo tipo. Pero si atendemos a la familia que se forma a lo largo de la película, la referencia podría indicar la búsqueda de una madre por parte de Jones para el niño que ha acogido.

Resulta igualmente relevante para el mundo externo del protagonista el hecho de que tras el comentario, y a pesar de haberse sentado el uno junto al otro (F30), se establece una tensión de amor/odio entre ambos, muy del estilo de las grandes comedias románticas de Hollywood en las que se establece una guerra entre los sexos. Esta relación se utiliza frecuentemete como comic relief, como anunciábamos anteriormente. Una vez más, todo vale en esta amalgama de referencias, citas y géneros: anything goes.

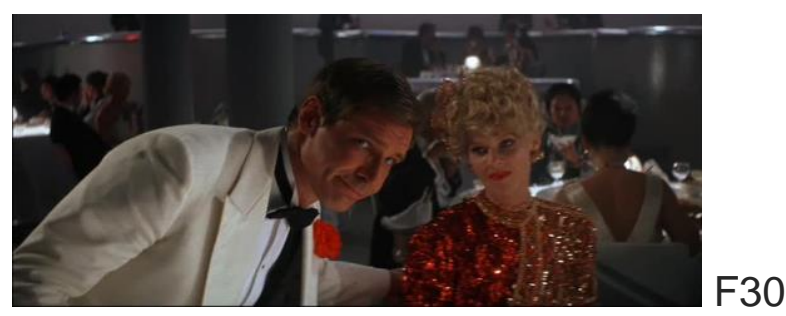

En un acto que no sorprende demasiado tras el desdén con el que había tratado a Marion cuando estaba secuestrada en Raiders, Jones toma como rehén a Scott amenazándola con un tenedor de puntas afiladas que atraviesan su vestido (F31). "I suggest you give me what you owe me, or "anything goes"', dice el arqueólogo, haciendo uso de la canción que acaba de versionar Scott. El plano de detalle en el que se muestra la mano de él apoyando el cubierto contra el pecho de 
ella (F32), aunque breve, goza de una gran carga sexual que está refrendada por los sonidos que emite ella cuando Jones mueve el tenedor hacia su cuerpo.
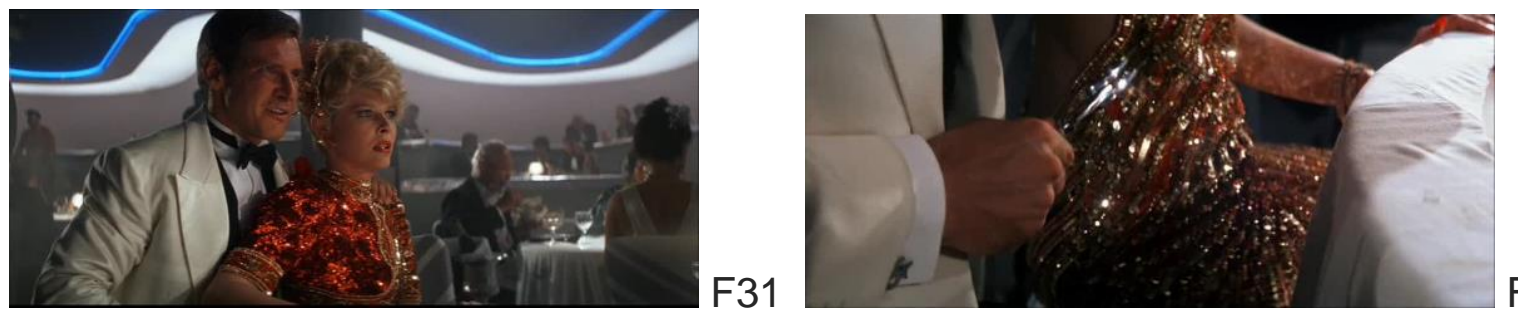

F32

El tratamiento que se le da al personaje de Scott raya la misoginia, ya que se la retrata como una chica absolutamente superficial y únicamente preocupada por su vestido de París, el diamante que vale una fortuna, la uña que se le ha roto o si el marajá tiene novia. Pero, no obstante, ella es la elegida para desempeñar el papel de madre en la familia que se constituye tras la escena en el club.

Ahí Round aparece sin llegar a ser presentado. Cuando Jones rebusca el antídoto en el vestido de Scott (F33), el niño, en alusión a la persecución en la que se encuentran, pero cargado de intenciones edípicas que refuerzan la idea de familia que se está formando, le dice al arqueólogo: "No time for love Dr Jones".

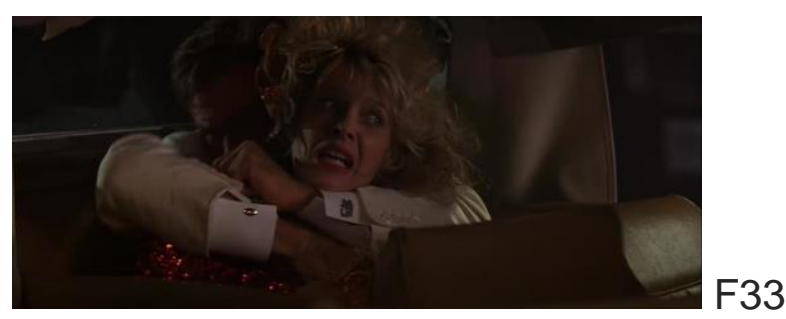

Volviendo a la relación entre los dos adultos, en el avión ella intenta poner en evidencia a Jones, diciéndole que desde que se encontraron no ha podido apartar los ojos de ella. Lo dice enfurecida, pero revestida con la chaqueta blanca de esmoquin con la que Jones había aparecido en el club Obi Wan (F34), signo de la necesidad de cambiarse de ropa por una menos llamativa, pero también signo de su atracción por el arqueólogo. 


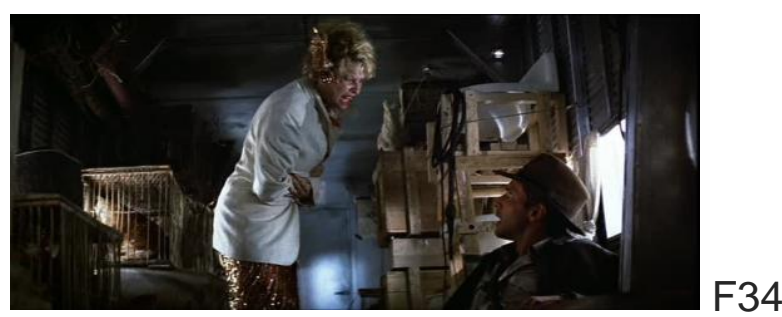

La familia se reúne en espacios reducidos: el inicial del coche, el avión, y a continuación la lancha neumática en la que logran escapar de la aeronave a punto de estrellarse (F35), en una peripecia que podría haber estado firmada por James Bond. Se reúnen pero de momento no se unen.

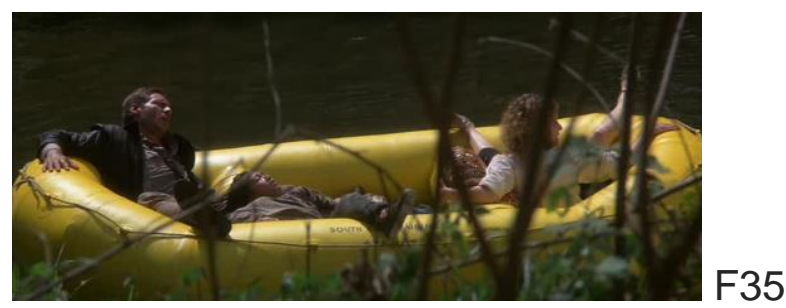

El momento de mayor intimidad como familia se produce en la jungla, cuando se explica la forma en la que fue recogido Short Round. Ahí Scott huye de los diversos animales que rodean el campamento, pero no le tiene miedo, por creer que se trata de la trompa del elefante, a una serpiente que rodea su cuello (F36). Jones se queda paralizado, incapaz de hacer nada. La escena contiene implicaturas sexuales, por la poca ropa que lleva ella y el hecho de que él se asuste al verla abrazada por el animal, y también religiosas, con la serpiente bajando del árbol como en el Génesis. La ofidiofobia que había manifestado el arqueólogo en Raiders regresa en esta ocasión del brazo de una mujer. La combinación de ambas, mujer y serpiente, dejan sin aliento a Jones, incapaz e impotente.

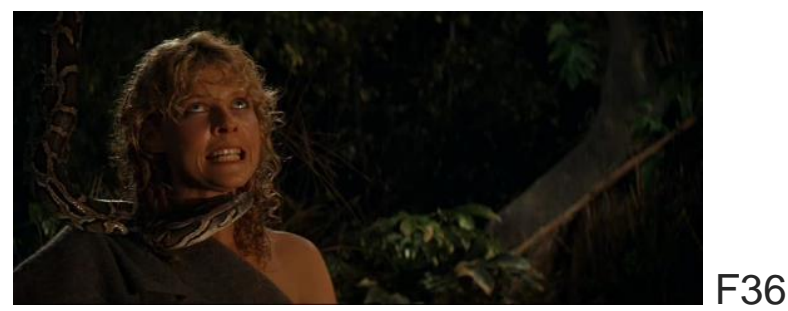


La escena en la que se explota con mayor ahínco la vis cómica de la relación que se establece entre Jones y Scott transcurre durante la noche en el palacio del marajá. Se produce un planteamiento clásico: la observamos a ella franqueando la puerta de su habitación: abriéndola y a la vez cerrándola (F37). Y de nuevo, en continuación directa de la escena que acabamos de comentar en el párrafo anterior, se hace alusión al Génesis, siendo el hombre quien en esta ocasión ofrece la manzana a la mujer. Ella come de la manzana con gran avidez (F38), fruto del apetito que se le ha abierto tras el festín exótico-monstruoso del que no ha podido deleitarse, y en adelanto de la relación sexual que supuestamente se va a producir a continuación.

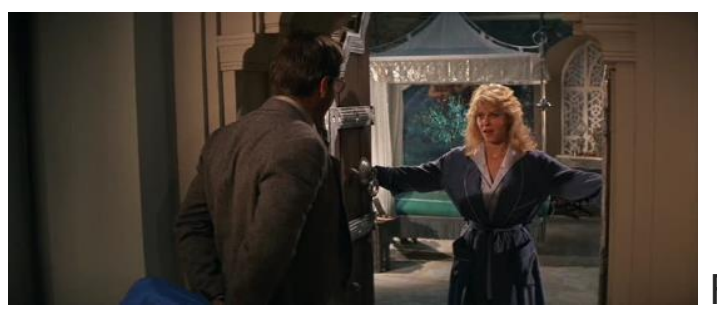

F37

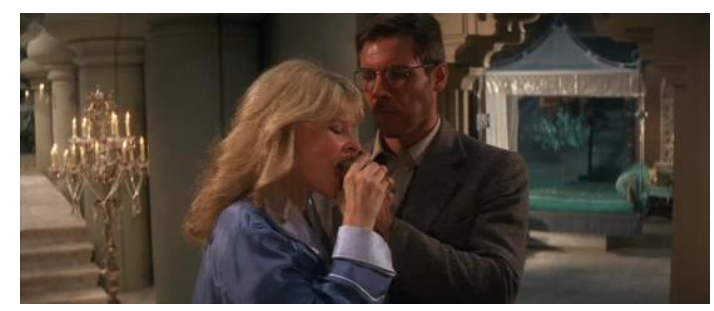

F38

La conversación entre ellos sube de tono hasta que se manifiesta sexualmente explícita. Jones, ataviado con su vestimenta más académica, que incluye sus gafas, se las quita, en lo más cercano a un striptease masculino que tenemos en la película (F39).

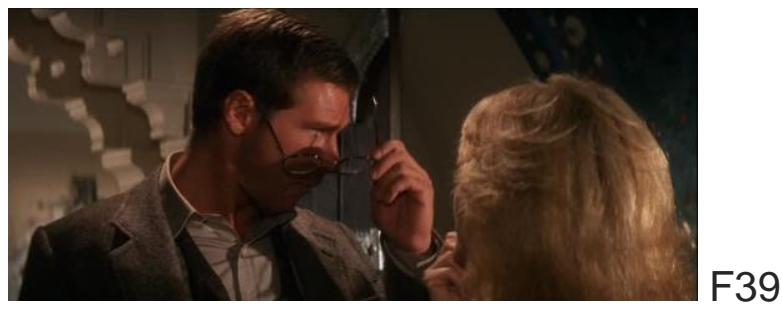

La tensión sexual se queda sin resolver, a pesar del beso que llegan a darse en la habitación de ella (F40). La explicación por la que no continúan no queda clara: ella parece totalmente dispuesta a seguir, y él cierra la puerta en señal de mayor intimidad, pero las palabras de Jones se interponen entre ambos. Parece que ella sí estaba preparada para los besos, pero no para pasar la noche con el arqueólogo. No obstante, su posición y sus ojos cerrados, en señal de confianza, así como el pilar decorado con un prominente relieve de una mujer y/o diosa con los pechos desnudos (pechos que tendrán que ser empujados para acceder al templo maldito), todo ello apunta a una entrega del cuerpo por parte de Scott, pero con una negativa 
derivada de su mente, que discrepa con la de Jones. Pero hay algo más que considerar: el hecho de que Jones no le corresponde a la chica cuando ella cierra los ojos esperando un beso (F41), lo cual ofende a Scott, que también se ve minusvalorada porque Jones aplaza el valorar su encuentro con ella hasta que haya pasado el experiment. De alguna manera es él quien la rechaza en primera instancia. Tras esa primera repulsa, las demás se pueden entender como una reacción en cadena ${ }^{7}$. Sin embargo, tras dirigirse cada uno a su aposento, preparan sus cuerpos para el encuentro amoroso en la esperanza de que sea el otro quien dé el siguiente paso. Esta guerra de sexos contribuye a resaltar la igualdad entre los mismos que se prodiga en esta escena, como señalábamos anteriormente.
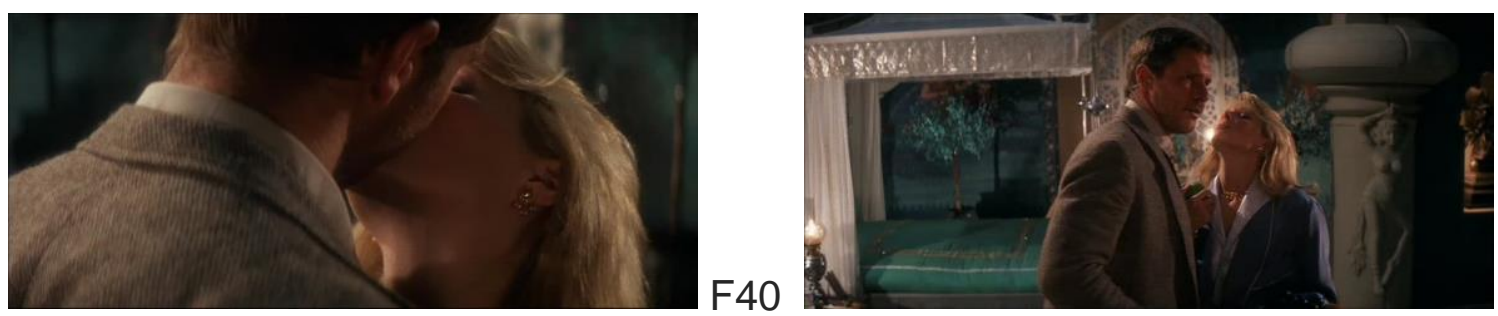

F41

El encuentro no se llega a producir, al ser interrumpido Jones en sus cavilaciones sobre si va a entrar o no en la habitación de ella por un sicario que acaba muriendo ahorcado con el látigo del arqueólogo, en una combinación de destreza y suerte por parte de Jones. Todo ello se produce en presencia de Round, que estaba dormido en la habitación de Jones: eso habría explicado en parte las reticencias de Jones a consumar el acto sexual, dada la presencia del niño. Pero cuando ese impedimento se despeja y Jones acude de nuevo a la habitación de Scott, no va en busca de la chica, sino de algo oculto que ni él ni los espectadores saben qué puede ser. Ahí es donde Jones empuja los pechos de la estatua del pilar (F42) y accede al templo maldito. No se da explicación de cómo ha averiguado el arqueólogo que allí puede estar el acceso al templo.

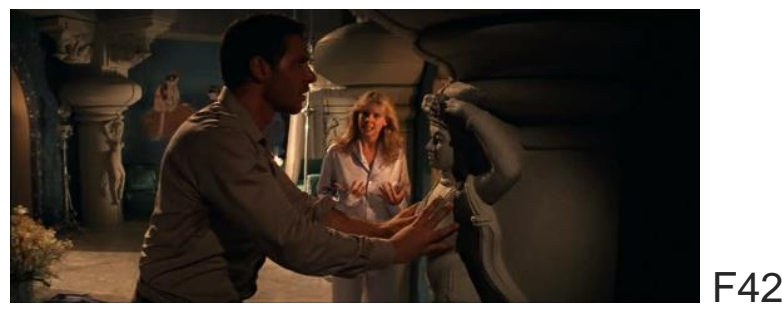

\footnotetext{
${ }^{7}$ Además una escena más explícita habría impedido que la película fuera calificada como PG en Estados Unidos. Precisamente tras el estreno de este film se propició, en parte auspiciada por el propio Spielberg, una nueva categoría, la $P G-13$, que es la que ha predominando en el cine comercial desde entonces.
} 
Resulta altamente significativo que el mayor peligro para la familia proceda del propio padre/héroe cuando éste ha bebido el brebaje que le pone en trance y hace que esté a punto de acabar con la vida de Scott.

Por otro lado, argumentalmente, el hecho de que el niño salve en dos ocasiones a Jones subraya la importancia del personaje de Short Round como aliado del héroe y como ese hijo putativo al que aludíamos más arriba.

En la escena de la vagoneta, ya mencionada anteriormente, la familia se sube a una atracción, pero poniendo en peligro la vida del más frágil, a quien se está a punto de desmembrar.

La escena final supone la re-unión de la familia, reforzada por el hecho de que es a unos niños a los que han salvado y liberado, con lo que esta familia que se ha creado se añade a las que habían sido rotas por el secuestro y explotación de los niños. Todo ello contribuye a conformar la idea de un padre salvador de los niños en la ficción y entretenedor de la audiencia, muy especialmente de los niños que hayan ido a ver la película acompañados de sus padres.

\section{El mundo interno en Indiana Jones and the Temple of Doom}

Como sucedía en Raiders, la interioridad de Indiana Jones se ve afectada por su relación con la religión y con el sentimiento religioso, hacia el que aparentemente profesa un gran descreimiento. En Temple of Doom es Wu Han, el camarero y ayudante de Jones, quien le dedica sus últimas palabras al arqueólogo antes de fallecer: "I've followed you on many adventures, but into the great unknown mystery I go first, Indy" (F43). Han separa la vida terrenal en la que se desarrollan las aventuras del misterio desconocido que supone la muerte, en parte coincidiendo con las creencias de Jones, quien tanto en esta película como en la anterior manifiesta varias veces su presunta desvinculación de sentimientos transcedentales. Las palabras de Han no apuntan hacia la interioridad del arqueólogo desde el exterior, sin que sea él quien se pronuncia sobre la misma.

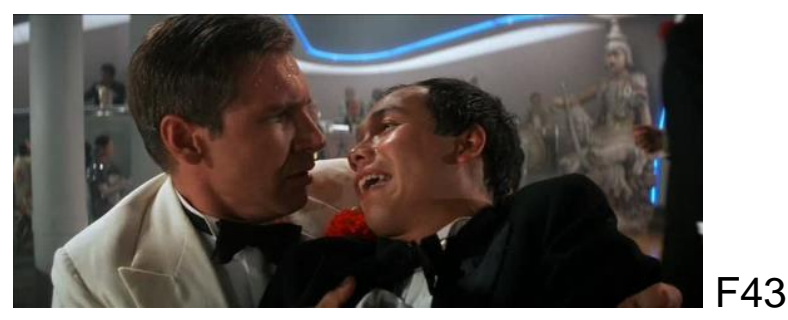


De nuevo sin llegar a acceder a su interior, pero intentando ver en él algo o alguien que trasciende y que va más allá de la mera exterioridad, destaca el momento en que los habitantes del pueblo rodean a Jones como si fuera un dios, un santo o un héroe, viendo en él aquello que pretende culminar sus aspiraciones (F44). El líder espiritual del pueblo corrobora esta impresión cuando le dice a Jones y a sus dos acompañantes "It was Siva who made you fall from the sky", y les encomienda la misión de rescatar las piedras sagradas. A la salida de ese encuentro, Jones le dice a Short Round que "it's just a ghost story". Pero lo que hace a Jones mostrar una mayor cara de preocupación es el hecho de que hayan secuestrado a los niños del pueblo: cuando uno de ellos escapa de su cautiverio, la primera persona que se encuentra en el pueblo es precisamente al arqueólogo: su papel de padre redentor/salvador de esos niños y de ese pueblo se hace cada vez más necesario. De hecho quien le demanda en última instancia esa acción es su propio hijo putativo, Short Round.

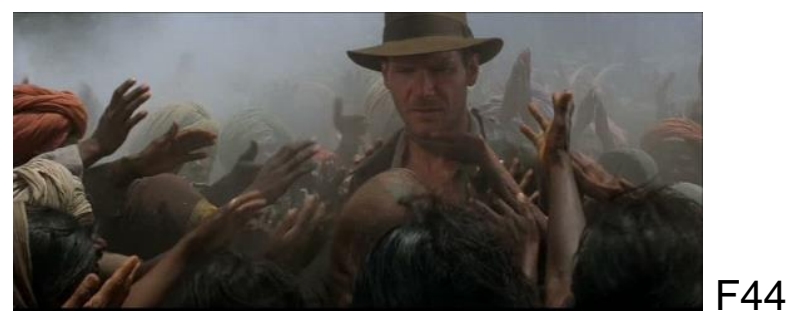

Durante gran parte de la película, Jones parece fascinado por el poder que pueden tener las piedras sagradas, que resume en las palabras "fortune and glory", poder que se ve reforzado por el valor económico que puedan tener, al supuestamente contener diamantes. Finalmente, cuando el líder espiritual le dice que ahora debe entender el poder mágico de la piedra robada, el arqueólogo lo admite diciendo "Yes, I understand its power now" (F45).

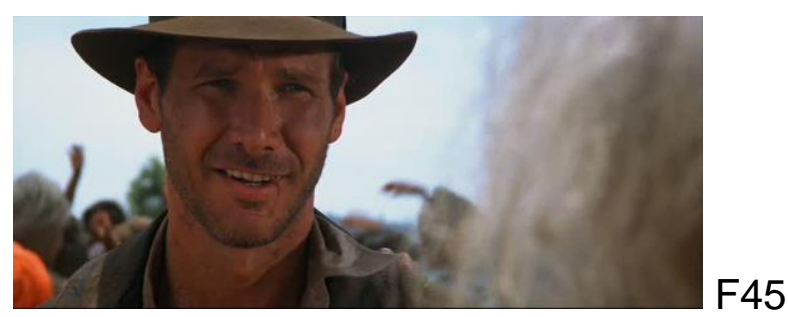

Esta afirmación en primer plano de Jones, en toma semi-subjetiva desde el pelo blanco del líder espiritual, sucede con la algarabía de todo el pueblo al fondo, corroborado por los planos previos y posteriores que confirman la alegría general del 
pueblo. Como sucedía en Raiders, Jones no tiene más remedio que creer a pesar de su falta de fe inicial.

\section{Conclusiones}

En la introducción de este artículo nos preguntábamos si lo que busca Indiana Jones en este texto fílmico es desarrollarse como padre y si esa búsqueda constituiría uno de los rasgos que caracterizan la masculinidad que representa el arqueólogo. No podemos afirmar con rotundidad que la paternidad, el ser o ejercer como padre, sea la búsqueda principal del doctor Jones, pero sí se podría observar que es la paternidad quien le busca a él, o, en otras palabras, que son los hijos figurados o putativos quienes le buscan y finalmente le encuentran. Ese poder de atracción para los niños que aparecen en la película le distancia de otras construcciones que había elaborado Harrison Ford en Return of the Jedi y Blade Runner, ya que incidían más en su afán aventurero que en sus capacidades paternas. Ese distanciamiento también se produce al principio de la película, cuando Jones aparece como un híbrido entre James Bond y Humphrey Bogart en Casablanca. El engaño que provoca el director con la mezcla de géneros fílmicos al principio del texto fílmico y la apariencia de Jones se rompe con la aparición de Short Round y la familia que se crea para la ocasión con Willie Scott en el papel de pareja de Jones y, en gran medida, madre también de los niños que rescatan al final. Como hemos podido comprobar, la relación que Indiana Jones mantiene con Short Round, así como el protagonismo que se le da al niño, contribuyen a que el público $P G-13$ se identifique aún más con la historia que se desarrolla ante sus ojos, a pesar del lado oscuro que muestran diversas imágenes en varias escenas de la película. La ayuda del niño es vital para el desarrollo del entorno de la acción, como lo sigue siendo en el entorno del mundo externo, como miembro de esa familia que se está intentando crear a lo largo de la película. El mundo interno de Jones se cifra, como sucedía en Raiders, alrededor de su supuesta falta de fe en todo aquello que no sea tangible y demostrable: lo que le convierte finalmente en aceptador de, al menos, el poder de la piedra sagrada que ha devuelto al pueblo, es precisamente el darse cuenta de que por encima de la fortuna y la gloria se sitúa el goce que le produce sentirse padre de los hijos que ha rescatado con su familia, Short Round y Willie Scott, en un plano que los alberga a todos y que cierra el texto fílmico (F46).

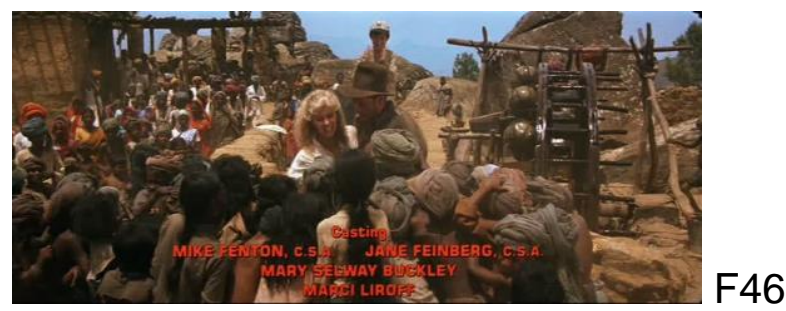




\section{Referencias}

$\begin{array}{llll}\text { Anything } & \text { Goes } & \text { Trivia. } & 2006 .\end{array}$ https://www.imdb.com/title/tt0027302/trivia?ref_=tt_trv_trv. Consultado el 28 de diciembre de 2006.

Buckland, Warren. 2006. Directed by Steven Spielberg: Poetics of the Contemporary Hollywood Blockbuster. Nueva York y Londres: Continuum.

Caldevilla Domínguez, David. 2005. El sello Spielberg. Madrid: Editorial Vision Net.

Capra, Frank (dir.). 1937. Lost Horizon. EEUU: Columbia Pictures Corporation.

Chatman, Seymour. 1986 (1978). Story and Discourse: Narrative Structure in Fiction and Film. Ithaca y Londres: Cornell University Press.

Connell, Raewyn. 1995. Masculinities. Cambridge: Polity Press.

Curtiz, Michael (dir.). 1942. Casablanca. EEUU: Warner Bros.

Díaz-Cuesta, José. 1998. "Searching for Traces of Myth in the Indiana Jones Saga". En Blesa, Túa (ed.). Mitos vol. II. Zaragoza: Asociación Española de Semiótica y Tropelías. 220-224.

Díaz-Cuesta, José. 2003. "A Reconstructive Analysis of the Masculinities Represented in Steven Spielberg's Jaws". British and American Studies 9, 179-187.

Díaz-Cuesta, José. 2005. "Masculinidades en Raiders of the Lost Ark". Revista de Ciencias de la Información 22.

Donner, Richard (dir.). 1985. The Goonies. EEUU: Warner Bros. y Amblin Entertainment.

Elkins, Merry (ed.). 1984. "Steven Spielberg on Indiana Jones and the Temple of Doom". American Cinematographer 65/7, 50-60.

Friedman, Lester D. 2006. Citizen Spielberg. Urbana y Chicago: University of Illinois Press.

Hamilton, Guy. 1964 (dir.). Goldfinger. Reino Unido: Eon Productions.

Kirkham, Pat, y Thumim, Janet (eds.). 1993. You Tarzan: Masculinities, Movies and Men. Londres: Lawrence and Wishart.

Loshitzky, Yosefa (ed.). 1997. Spielberg's Holocaust: Critical Perspectives on Schindler's List. Bloomington: Indiana University Press. 
Lucas, George (dir.). 1983. Return of the Jedi. EEUU: Lucasfilm.

Rissik, Andrew. 1984. "Steven Spielberg: Indiana Jones and the 007 myth". Films and Filming 363, 13.

Sánchez-Escalonilla, Antonio. 1995. Steven Spielberg. Barcelona: Royal Books.

Sánchez-Escalonilla, Antonio. 2005. Steven Spielberg: Entre Ulises y Peter Pan. Madrid: Cie Dossat 2000.

Scott, Ridley (dir.). 1982. Blade Runner. EEUU, Hong Kong y Reino Unido: Ladd Company, Shaw Brothers y Warner Bros.

Silet, Charles L. P. (ed.). 2002. The Films of Steven Spielberg: Critical Essays. Lanham, Maryland y Oxford: Scarecrow Press.

Spielberg, Steven (dir.). 1974. The Sugarland Express. EEUU: Zanuck/Brown Productions y Universal Pictures.

Spielberg, Steven (dir.). 1981. Raiders of the Lost Ark. EEUU: Lucasfilm y Paramount Pictures.

Spielberg, Steven (dir.). 1984. Indiana Jones and the Temple of Doom. EEUU: Lucasfilm y Paramount Pictures.

Spielberg, Steven (dir.). 2002. Catch Me If You Can. EEUU: Dreamworks SKG, Amblin Entertainment, Kemp Company, Splendid Pictures y Parkes/MacDonald Productions.

Spielberg, Steven (dir.). 1993. Schindler's List. EEUU: Amblin Entertainment y Universal Pictures.

Spielberg, Steven (dir.). 1998. Saving Private Ryan. EEUU: Amblin Entertainment, Dreamworks SKG, Mark Gordon Productions, Mutual Film Company y Paramount Pictures.

White, Susanna. 2004. "20-somethings and The Goonies". IMDb User Reviews of The Goonies. http://www.imdb.com/user/ur3981981/?ref_=tt_urv. Consultado el 28 de diciembre de 2006. 